\title{
O Projeto Político-Pedagógico como Parâmetro na Avaliação dos Cursos de Graduação: A Experiência do Conhecer, Avaliar, Melhorar
}

\author{
Arlindo "Piu" Ornelas Figueira Neto* \\ Escola de Comunicações e Artes da Universidade de São Paulo \\ * Autor para correspondência: lindopiu@usp.br
}

\section{RESUMO}

Ao mesmo tempo que se reconhece a importância da avaliação discente dos cursos de Graduação, percebe-se a dificuldade em medir a eficácia de uma formação, pelas opiniões de quem ainda não tem uma visão completa de suas necessidades formativas. Essa dissonância foi o ponto de partida do projeto Conhecer, Avaliar, Melhorar, que focou a avaliação discente com base na divulgação e discussão do PPP da Habilitação em Publicidade e Propaganda da ECA. Numa primeira instância avaliou-se o próprio PPP e sua adequação às demandas contemporâneas e, num segundo patamar, foi avaliado o quanto o PPP estava sendo reproduzido nas salas de aula. Apesar das várias dificuldades enfrentadas, tanto por variáveis de livre escolha, como por fatores incontroláveis, foi possível concluir que a ideia é perfeitamente válida e adequada para promover a avaliação discente num nível mais objetivo e consciente.

Palavras-Chave: Avaliação do Ensino de Graduação; Avaliação de Projeto Político-Pedagógico; Metodologias de Avaliação Discente.

\begin{abstract}
We recognize the importance of student evaluation on our undergraduate courses, but, at same time we face the difficulty of measuring the effectiveness of the formation by the opinions of those who don't have a complete and a prospective view of their education needs. This dissonance was the starting point of the Conhecer, Avaliar, Melhorar project, that was focused on undergraduate student evaluation, based on the dissemination and discussion of the PPP (Political Pedagogic Project) of the course of Propaganda and Advertising of ECA (School of Arts and Communication). In a first step, the PPP itself was evaluated as its suitability to contemporary demands of employability; and, in a second level, it was questioned if and how the PPP was applied on disciplines and in the classrooms. Despite the various difficulties faced both by free choice variables, such as uncontrollable factors, it was possible to conclude that the idea is perfectly valid and appropriate for promoting student assessment of their courses in a more objective and conscious level.
\end{abstract}

Keywords: Undergraduate Courses Evaluation; Evaluation of Pedagogical Project of Courses; Evaluation of Undergraduate Courses by Students.

\section{Introdução}

Vai longe o tempo em que os cursos tinham seus desempenhos avaliados univocamente pelas notas e aprovações atribuídas aos alunos. Desnecessário hoje reafirmar a importância da avaliação discente para os cursos e disciplinas de Graduação. Ainda que seja apenas mais uma das variáveis a serem consideradas, tem tido crescente relevância por todos os ângulos (desde a constatação de falhas pedagógicas até à mensuração da satisfação dos alunos)
- e por isso mesmo é assunto recorrente nas CoCs, CGs e demais colegiados na Graduação da USP.

As avaliações discentes completam um processo de interação entre os cursos e seus alunos, que transformaram o antigo posicionamento passivo do corpo discente num equilíbrio entre os sujeitos da aprendizagem:

$\mathrm{O}$ processo de ensino-aprendizagem visto da óptica discente deve ser valorizado (LOUSADA 
\& MARTINS, 2005), uma vez que a construção do saber é uma via de mão dupla em que aluno e professor devem estar em sintonia, para que o conteúdo proposto seja absorvido com sucesso e futuramente aplicado no mercado de trabalho ou na vida social do aluno. Nesse sentido, teoria e prática se alinham na vida acadêmica e profissional do discente. (FERREIRA et al., 2016, p. 32)

Ainda que a importância tenha sido reconhecida há algum tempo por diferentes unidades da USP - se não por todas -, as avaliações discentes ainda não foram institucionalizadas em várias delas. Tampouco a Universidade logrou êxito em implantar uma sistemática de avaliação. Em 2009, o Siga - Sistema Integrado de Indicadores da Graduação - pretendeu institucionalizar a avaliação discente on-line e, após vários anos - uma tentativa de maior descentralização (com o Siga Unidades, em 2012), acabou sucumbindo, pela generalizada falta de participação discente ${ }^{1}$.

$\mathrm{Na}$ ECA, apesar de muitos esforços institucionais, o Siga nunca conseguiu registrar participações discentes que fossem, ao menos, razoáveis. Em 2011, após uma série de análises, tomamos a iniciativa de consultar a coordenação do Ciclo Básico (Biênio) da Epusp, professor André Antunha, sobre a possibilidade de ajuda na extensão de seu sistema de avaliação (a chamada CDE - Consulta Discente sobre o Ensino) à ECA. A CDE vinha sendo realizada há algum tempo na Poli e registrava resultados muito bons. Foram acordados o "empréstimo" do então Coordenador Pedagógico, Giuliano Olguim, e o fornecimento e processamento dos formulários óticos aos departamentos que se interessaram - CJE (Jornalismo e Editoração) e CRP (Relações Públicas, Propaganda e Turismo) da ECA. Apesar da boa participação e dos bons resultados alcançados em três semestres consecutivos no GRP, face à impossibilidade da continuidade do apoio por parte da Poli e à dificuldade de se manter a iniciativa com recursos próprios, as avaliações foram interrompidas. Falando especificamente da habilitação em Publicidade e Propaganda, para a qual implementamos esse sistema de consulta, foi fácil identificar que muitas das críticas emanadas dos alunos tinham origem numa expectativa equivocada sobre o conteúdo ou sobre os objetivos pedagógico-formativos das disciplinas ou mesmo do curso. Como os alunos imaginavam um curso bastante diferente da realidade formativa definida para a carreira, o que se oferecia não era plenamente compreendido e gerava insatisfação discente.

Particularmente nessa habilitação, as expectativas dos alunos são bastante diferentes da realidade do curso: a carreira “... é vista parcial e principalmente pelo prisma estereotipado da criatividade... $\mathrm{Na}$ ausência de informações mais concretas... predomina a 'certeza' de que existe na escola uma fórmula ou, nas palavras deles, 'as técnicas' para persuadir os consumidores" (FIGUEIRA NETO, 2006, pp. 40-41). Os alunos ingressam com a ilusão de que a escola irá "lapidar" na prática cotidiana a sua criatividade. E ignoram que uma formação em Comunicação Publicitária envolve conhecimentos humanísticos muito mais profundos, que a simples prática orientada é incapaz de consubstanciar.

A imagem do curso de Publicidade e Propaganda é, portanto, bem diferente da sua realidade. E imaginamos que isso aconteça em maior ou menor grau, em todos os cursos de nossa Graduação. No dizer de Kotler (1994, p. 58): "As pessoas tendem a formar imagens das escolas baseadas em informações frequentemente limitadas, e mesmo imprecisas...". Substituindo-se por cursos e/ou disciplinas, pode-se dizer que, à medida que a imagem destes não se encaixa naquilo que foi idealizado, cria-se uma dissonância entre o esperado e o real que, se não for muito bem administrada, pode resultar em consequências negativas bastante significativas. E que, no caso, para quem espera um cenário de aprendizado eminentemente prático e mesmo lúdico, a realidade de um aprofundamento teórico ou a necessidade de contínuas reflexões analíticas irão provavelmente provocar várias quebras de expectativas.

Por um lado, tem-se a absoluta necessidade de incorporar os alunos à avaliação do curso; ao mesmo tempo, a condição avaliativa deles não é a mais abalizada, já que feita sem o conhecimento de mui- 
to daquilo que fundamenta e garante a boa formação. "Ninguém pode obter o que não conhece" (RIBEIRO, 1998, p. 73), o que confunde inegavelmente os caminhos formativos que devem ser seguidos e, claro, interfere negativamente nas avaliações. Há, pois, a necessidade de expor os arcabouços formativos e discuti-los com o público discente que, em tese, é o maior interessado neles. Para isso, os Projetos Político-Pedagógicos dos cursos surgem como os conteúdos ideais para promover essa informação, uma vez que as formações se estruturam e ocorrem a partir deles. Tornar os PPPs conhecidos dos alunos foi, portanto, o ponto central do projeto que desenvolvemos.

\section{O Início}

O nome do projeto, Conhecer, Avaliar, Melhorar, deixa claros seus propósitos e a sequência de suas intenções. Ele abrange as três fases ideais: primeiro, tornar conhecido dos alunos o Projeto Político -Pedagógico do Curso que norteia sua formação; depois, fazer sua avaliação e a do curso, baseada nos tópicos que compõem o PPP; e finalmente, promover melhorias a partir das discussões realizadas. Uma ideia, em tese, simples e direta, mas que, segundo mostra a experiência, deve cercar-se de bastante cuidado para ser eficiente.

O Projeto recebeu seis bolsistas do PUB - Programa Unificado de Bolsas, em 2015, alunos de Publicidade e Propaganda que ajudaram a detalhar sua formatação e o operacionalizaram com base nas orientações da coordenação. É necessário destacar a dedicação e a competência deles: Bruna Magalhaes
Kater, Carolina Reis Gaudencio, Felipe Rodrigues de Freitas, Gabriel Furlan Passos, Laura Hanek de Albuquerque Ferreira Pinto e Sergio Barbosa Junior, a quem aqui novamente agradecemos a colaboração. Suas atuações foram fundamentais, à medida que eles próprios tinham vivência da situação e dos problemas a serem enfrentados e puderam antecipar soluções. Além disso, a interação com os colegas discentes facilitou encontrar o tom ideal da comunicação com os alunos de Publicidade e Propaganda. Há de se agradecer a eles também a obstinação com que enfrentaram os imprevistos e de se louvar a criatividade, usada para contornar os obstáculos encontrados. É inegável também que nossa experiência docente na ECA, em particular em Publicidade e Propaganda, sinalizava que, embora informalmente o curso fosse sempre discutido pelos alunos, não seria tranquilo obter deles um engajamento sistemático para conhecer e avaliar o PPP e o curso oferecido.

O projeto iniciou-se em agosto de 2015, com uma campanha de comunicação destinada a torná-lo conhecido e, ao mesmo tempo, despertar a curiosidade para o Projeto Político-Pedagógico de Publicidade e Propaganda, motivando-os a conhecê-lo e a participar do Conhecer, Avaliar, Melhorar. A criação de uma identidade visual para o projeto foi a primeira atividade da campanha de comunicação e buscou identificar o projeto aos alunos e à ECA e facilitar seu reconhecimento em todos os contatos. Para isso, foi criada uma sigla - CAM - e a identidade visual foi baseada na logotipia da Escola. A marca desenvolvida pode ser vista a seguir.

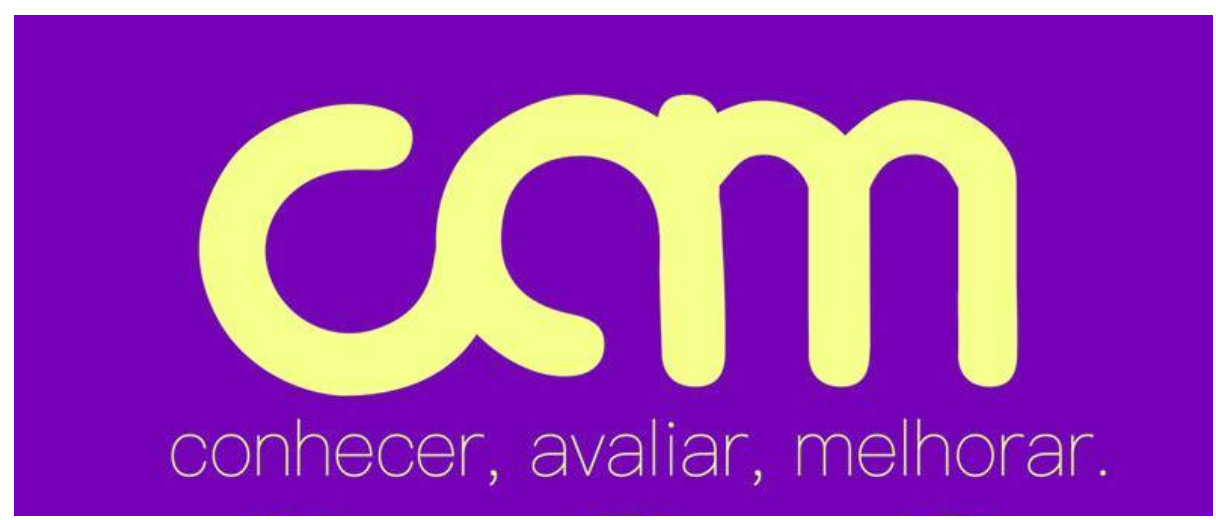


É claro que a identidade visual isolada não falaria muito sobre o projeto. Foi necessário explicá-lo e criar curiosidade para atrair a atenção discente. Quem circula pelas unidades da USP sabe que, ao menos na maioria delas, é difícil fugir ao excesso de mensagens das "mídias" disponíveis (quadros de avisos, tabuletas, faixas, banners etc.). Para fugir desse cenário de poluição de informações, optamos por criar uma campanha em que "criação e mídia" fossem integradas, ou seja, em que a mensagem fosse inevitavelmente vista e sua colocação potencializasse seu efeito, com um componente beirando o lúdico. Isso foi conseguido com a criação de cartazes A3 (420 x $297 \mathrm{~mm})$, que foram colados nas portas de todas as salas de aula do departamento, onde obrigatoriamente os alunos de $\mathrm{Pu}$ blicidade e Propaganda teriam que adentrar. Os bolsistas pensaram a campanha de uma forma bastante criativa: na parte exterior das portas, colaram um cartaz teaser, composto por um meme das redes sociais, e na parte interna, sempre um mesmo "cartaz-resposta", informando sobre o projeto e dando as direções para a participação. Os exemplos de cartazes a seguir explicam melhor como se deu a campanha:

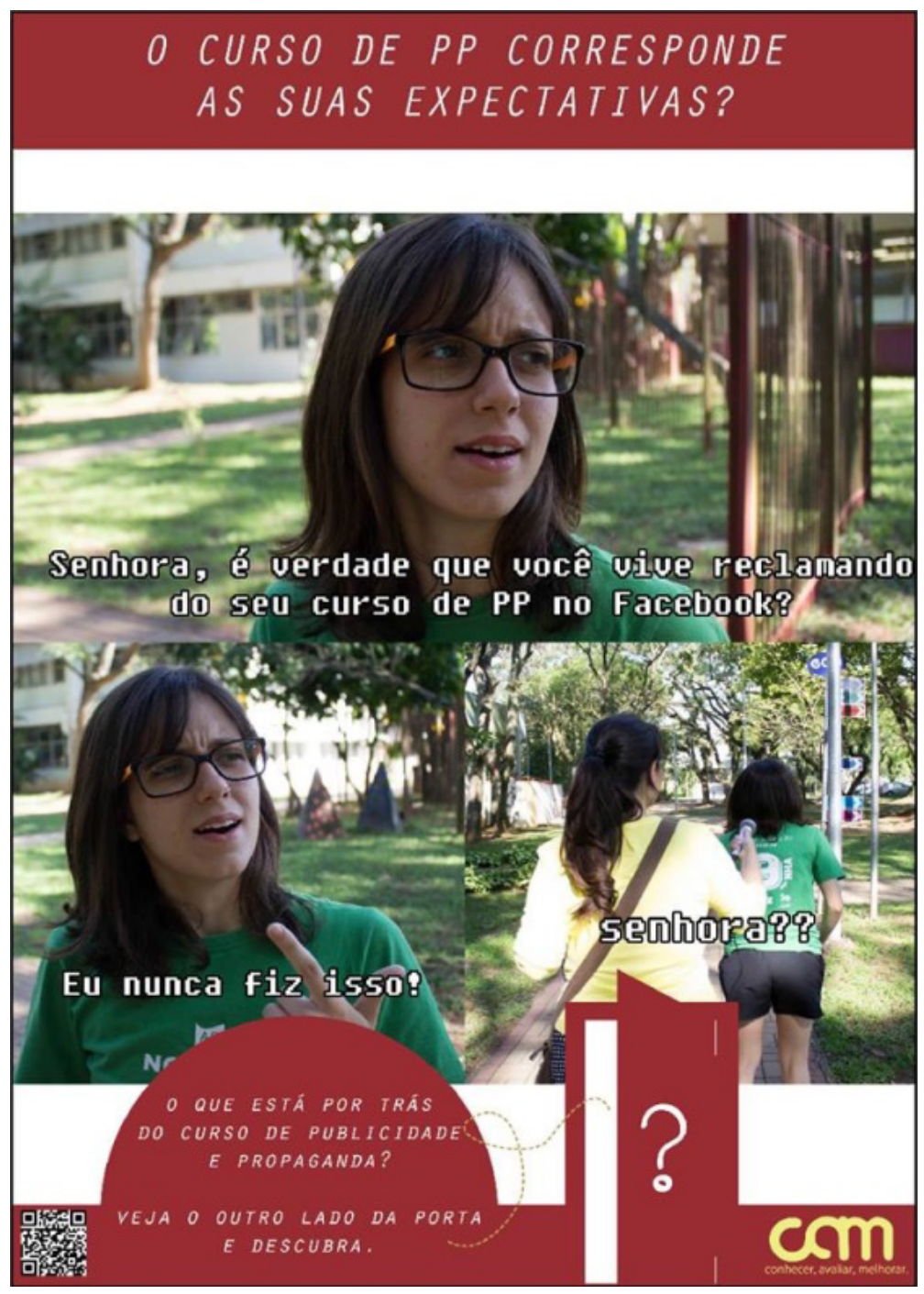

Cartaz criado por inspiração de um "meme" originado por uma reportagem do Jornal Nacional, em que uma funcionária pública era flagrada fraudando seu ponto e depois, ao ser questionada, fugia da repórter. Este cartaz foi afixado na parte frontal das portas das salas e, em sua parte inferior, remetia para o lado interno das portas, onde estava o "cartaz-resposta", que pode ser visto a seguir. 


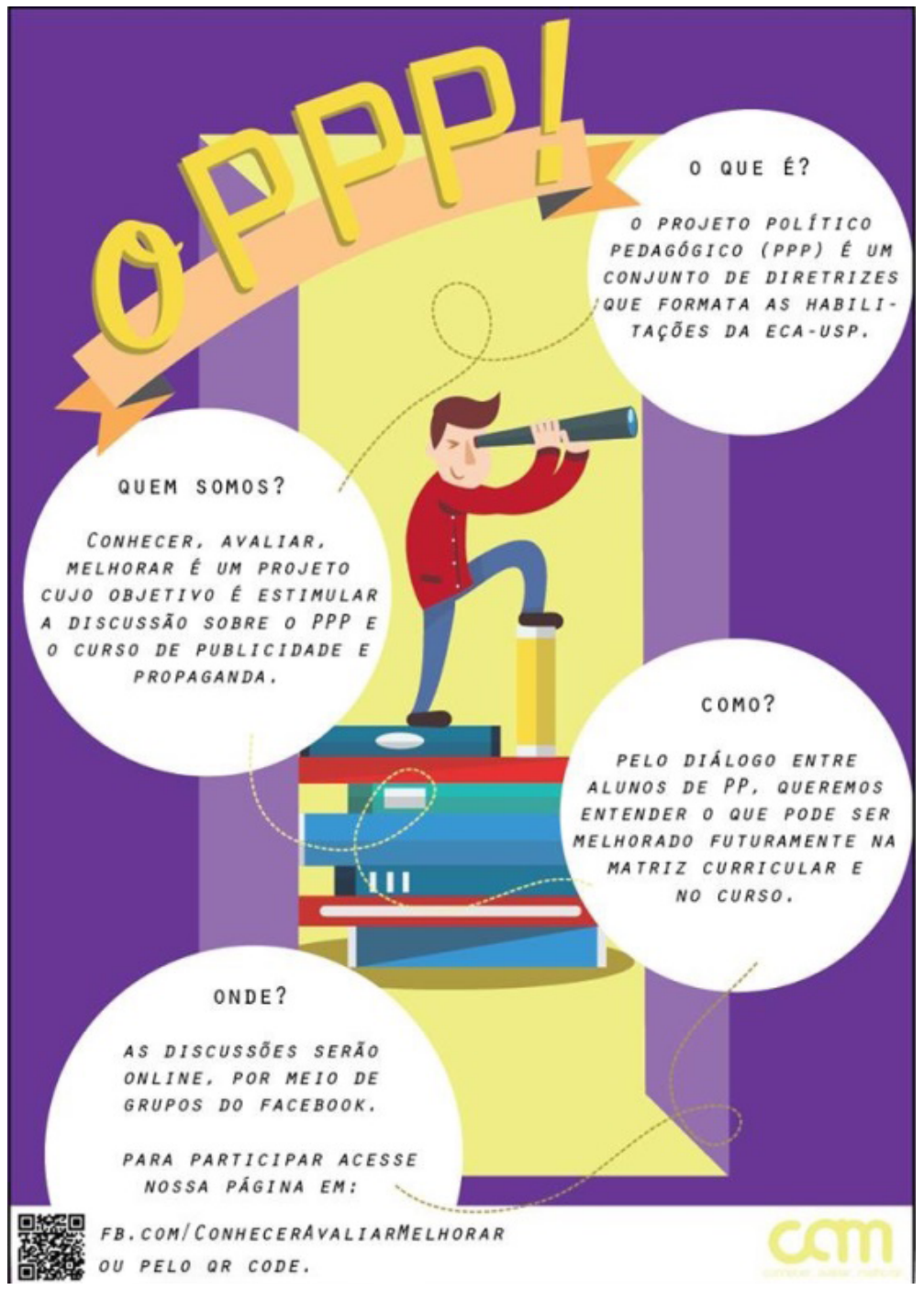

Este cartaz, o "cartaz-resposta", foi afixado em todas as portas, nas faces interiores. Explica o que é o PPP, apresenta o projeto Conhecer, Avaliar, Melhorar e indica a forma de participação.

Na parte inferior esquerda, informa o endereço da página do projeto no Facebook e disponibiliza um $\mathrm{QR}$ code para acesso dos alunos.

Como se pode perceber pelo "cartaz-resposta", as discussões sobre o PPP foram centradas no Facebook. Inicialmente o projeto previa a construção de "bulletin boards" para as discussões on-line, porém os bolsistas alertaram à coordenação que isso exigiria maior motivação dos alunos, pelo fato de serem necessários acessos específicos a essas plataformas. Como disseram eles, o Facebook já era permanentemente acessado por todos e, tendo sido criados grupos específicos para as discussões de cada turma ( $1^{\text {os }}, 2^{\text {os }}$ e $3^{\text {os }}$ e $4^{\text {os }}$ anos $)$, todos os alunos eram notificados a cada inserção de uma nova postagem e de um novo comentário, sendo natural e imediato o acesso a eles.
Uma tarefa bastante importante foi a definição da forma de apresentação do PPP para a discussão discente. No caso de Publicidade e Propaganda, a habilitação teve seu reconhecimento pelo CEE renovado em 2016, e o Projeto (atualizado em 2015) conta com 96 longas páginas. Obviamente nem o mais motivado aluno estaria disposto a estudá-las para as discussões. Em primeiro lugar tratou-se de identificar, no PPP, a sua essência: os princípios formativos, as competências e habilidades buscadas, o perfil desejado para o egresso, a descrição do mercado de trabalho, os parâmetros pedagógicos e a matriz curricular. $\mathrm{O}$ segundo passo foi buscar o que há de mais importante nessa essência, 
fazer um resumo dos pontos e redigi-los numa linguagem mais coloquial. Tudo para facilitar a compreensão e estimular potencialmente as discussões. Foram assim elencados e preparados oito pontos para que fossem debatidos pelos alunos do curso, num período de seis meses (outubro e novembro de 2015 e de março a junho de 2016). Houve também a preocupação de se definir a ordem dos pontos a serem colocados em discussão: primeiro os que tratavam da formação numa perspectiva mais geral, afunilando depois para os que a definiam mais especificamente. Tomou-se o cuidado de não introduzir mais de um tema para ser debatido simultaneamente nos grupos do Facebook, para concentrar a discussão num tema até sua exaustão.

\section{Colocando o Projeto em Funcionamento}

Afixados os cartazes nas portas das salas de aula, houve uma grande repercussão positiva por parte dos alunos em torno do Conhecer, Avaliar, Melhorar. Foram criados os três grupos no Facebook e logo depois, em outubro de 2015, introduzido o primeiro tema a ser debatido: o referente à atual miscigenação das formas de Comunicação Mercadológica e à necessidade de se formar um profissional multidisciplinar, habilitado a dominar todas elas. O texto do PPP, numa linguagem bem acadêmica, foi vertido numa linguagem mais coloquial: "A Publicidade hoje, deve trabalhar em conjunto com outras formas de Comunicação. Pela transformação da área, uma atuação interdisciplinar é fundamental para a construção de soluções mais eficazes para os problemas de Comunicação". E, no Facebook, depois de um tempo destinado às manifestações espontâneas dos alunos, foram paulatinamente introduzidos questionamentos: 1) Vocês concordam que a Publicidade deve atuar junto com outras formas de comunicação? 2) Até agora, vocês têm percebido uma formação interdisciplinar no curso de PP? 3) Vocês sentem que estão sendo preparados para solucionar problemas de comunicação levando em conta todas as transformações que a área de publicidade vem sofrendo? Ou seja, têm preparação para solucionar e entender problemas atuais/modernos da comunicação, considerando todas as transformações que têm ocorrido?
O tema despertou grande interesse e foi bastante discutido entre os alunos, mas, paradoxalmente, a discussão ocorreu fora dos grupos do Facebook. Foram registrados e relatados pelos bolsistas vários comentários de colegas, ora negativos, ora positivos, mas sem que isso significasse postagens para discussão. Esse primeiro tema teve apenas sete postagens de comentários nas turmas do $2^{\circ}$ ano, cinco nas do $1^{\circ}$ e apenas um comentário nas turmas do $3^{\circ}$ e $4^{\circ}$ ano. Apesar de o prazo para a discussão terse estendido e de vários outros memes terem sido divulgados para chamar os alunos à pesquisa, a participação foi pífia e pouco significativa.

Isso provocou uma mudança na sequência do projeto: ao invés de serem introduzidos novos temas para discussão, optou-se pela consulta aos alunos para a verificação das razões da não participação no Facebook. Isso foi feito reunindo-se os alunos em quatro focus groups, moderados pelos bolsistas, ainda em novembro de 2015. Foram dinâmicas bem rápidas e objetivas, em que se expôs o baixo engajamento dos alunos nas discussões e, em consequência, a possibilidade de o projeto não resultar nas esperadas melhorias do curso. As justificativas alegadas foram predominantemente a falta de tempo e a descrença na possibilidade de mudanças no curso, a curto prazo. $\mathrm{Na}$ análise das dinâmicas, contudo, pode-se perceber que os reais motivos para a não participação nas páginas de discussão do Facebook envolveram o receio do registro das posições individuais. Pode-se explicar isso pelo fato de as postagens que iniciaram os debates terem sido bem pensadas e elaboradas, além de logicamente bem fundamentadas, tornando difíceis eventuais contestações, mesmo que parciais, e, de certa forma, dispensáveis os endossos. Nesse sentido, preferiu-se majoritariamente a discussão informal, nos corredores do departamento, ao registro "oficial" no Facebook. E, num segundo plano - que se pode entender - tão ou mais importante que o já comentado, pode-se considerar que a rede social é um espaço de contato permanente, mas não perfeitamente adequado para manifestações mais profundas e/ou reflexivas: normalmente os comentários são mais epidérmicos e breves, longe 
do que os alunos classificam como "textão". Assim, o que em tese seria o cadinho perfeito para fundir os comentários e opiniões dos discentes mostrouse bastante inadequado para a tarefa.

\section{Uma Mudança de Rumos}

Em janeiro e fevereiro de 2016, houve tempo para a reformulação da pesquisa original e chegouse ao consenso de que a continuidade do projeto deveria realizar-se de uma forma mais tradicional: num primeiro momento, apresentar os pontos do PPP e discuti-los presencialmente; e, num segundo, relacionar as várias considerações e avaliar quantitativamente a concordância/discordância deles por meio de questionários on-line.

Foram, dessa forma, realizadas no início do primeiro semestre letivo de 2016 quatro dinâmicas de grupo com as turmas - dos então $2^{\circ}$ e $3^{\circ}$ anos -, nas quais foram apresentados e discutidos seis diferentes pontos do PPP, relativos às habilidades e competências, ao perfil do egresso, ao mercado, às disciplinas do curso e, em todas elas, em que grau o curso - da forma como estava sendo ministrado - tinha correspondência com seu Projeto Político-Pedagógico. As dinâmicas foram realizadas nas salas de aula, com a concordância dos docentes, que gentilmente abreviaram suas aulas. Ao contrário da fraca participação virtual no Facebook, as dinâmicas, gravadas em áudio para possibilitar análise posterior -, tiveram grande participação nas turmas. Os conteúdos do PPP selecionados para as discussões foram discutidos de forma exaustiva e serviram de base para a discussão de problemas específicos do curso, como comportamentos pedagógicos de alguns docentes, defasagem de conteúdos e, mesmo, a perspectiva de obrigatoriedade de estágio numa futura reforma curricular.

Constituiu-se, através das dinâmicas, um excelente conjunto de informações qualitativas, tanto sobre as direções traçadas para a formação (o PPP), como para a sua aplicação prática, ou seja, sobre a percepção discente do que realmente era trazido até eles, no dia a dia do curso. Pretendiase, a partir daí, aplicar dois questionários on-line para a quantificação das opiniões dos alunos, mas a eclosão de uma greve discente, em meados de maio de 2016, forçou uma redução nos trabalhos, que foram resumidos à aplicação de um único questionário.

Ainda que tenha sido elaborado com uma redução na sua amplitude, o questionário trouxe resultados bem interessantes. Mediu-se, em primeiro lugar, o que os alunos pensavam a respeito da divulgação do Projeto Político-Pedagógico, e isso não deixou dúvidas: $87,5 \%$ dos alunos respondentes consideraram importante que o PPP fosse mais divulgado, enquanto 37,5\% disseram que o projeto Conhecer, Avaliar, Melhorar conseguiu fazer esse papel. Na opinião de $58,3 \%$, o projeto cumpriu isso apenas parcialmente, ou seja , deveria ter uma divulgação mais eficiente.

Quanto à divulgação do PPP aos alunos, você acha que:

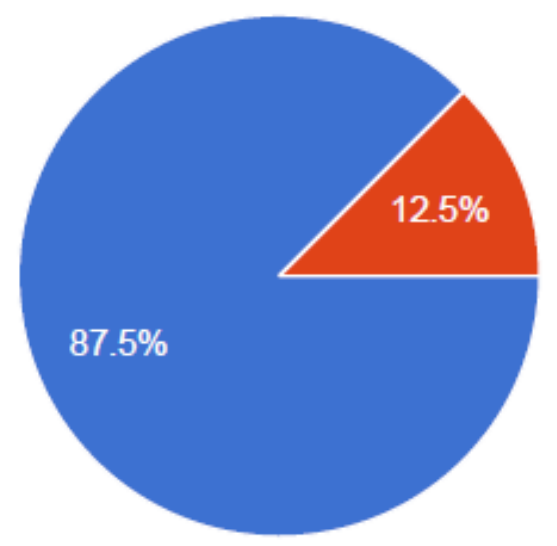

É importante que fosse muito mais divulgado para os alunos do curso

Poderia ter divulgado seus pontos principais

Sua divulgação não é fundamental (vá para pergunta 4) 


\section{E quanto à divulgação do PPP pelo Conhecer, Avaliar, Melhorar?}

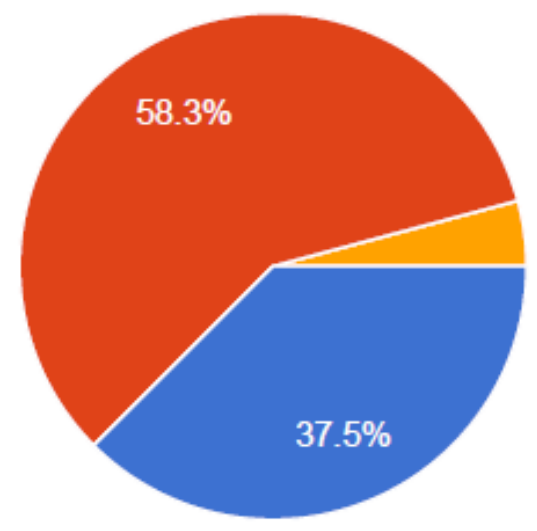

Como já mencionado, a avaliação discente pelo PPP pode se dar sob duas perspectivas, tanto sob o prisma da adequação do Projeto, como da sua aplicação na prática. Essa duplicidade foi avaliada em vários pontos no caso da Habilitação em Publicidade e Propaganda. Um deles foi o questionamento se, como aludido no PPP, o ensino de Publicidade deveria prever uma formação mais multidisciplinar, que focasse também o aprendizado de outras formas de Comunicação Mercadológica. Nesse ponto, a maioria $(70,8 \%)$ mostrou concordância absoluta
Conseguiu entender bem os pontos principais do PPP

Entendeu apenas razoavelmente o PPP

Não entendeu bem os pontos do PPP

Não entendeu, nem sabe pra que serve o PPP

A Publicidade hoje deve trabalhar em conjunto com outras formas de Comunicação... Você diria que o PPP, neste ponto:

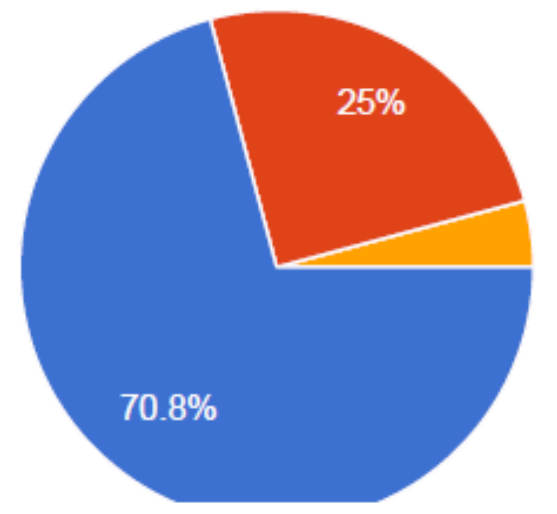

com o que é dito no Projeto, reconhecendo que esta é hoje uma exigência do mercado e, consequentemente, da formação. Mas, logo na sequência, perguntados sobre se o PPP realiza isso na prática, houve uma maciça discordância dos alunos: 75\% assinalaram que o curso se enquadra apenas parcialmente no que o PPP teoriza, enquanto os outros $25 \%$ acreditam que ele se distancia muito da realidade, sobre esse ângulo formativo. Os gráficos subsequentes ilustram bem essa dissonância entre o PPP e a realidade do curso, na visão dos alunos:

\section{E esse aspecto do PPP está presente no curso de Publicidade?}

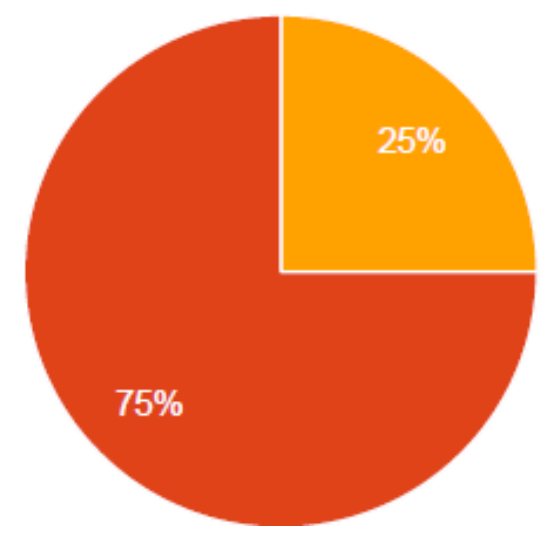

Está totalmente correto com a realidade de mercado

Está parcialmente correto

Deixa a desejar com relação à realidade de mercado

Vai na contramão do que acontece no mercado 
Vários outros aspectos foram avaliados pelos alunos no questionário aplicado, e as respostas evidenciaram outras dissonâncias entre o idealizado no PPP e o que é percebido pelos discentes. Num outro caso, ante as afirmações de que "a formação na ECA tem um caráter teórico-prático" e de que "as disciplinas existentes são combinações em doses variadas de reflexão crítica e do fazer técnico", notou-se uma grande demanda por maior presença da prática nas disciplinas ministradas. Os resultados obtidos mostram que a proporção de teoria e prática deve ser melhor pensada.

\section{Reflexão Crítica x Fazer Técnico}

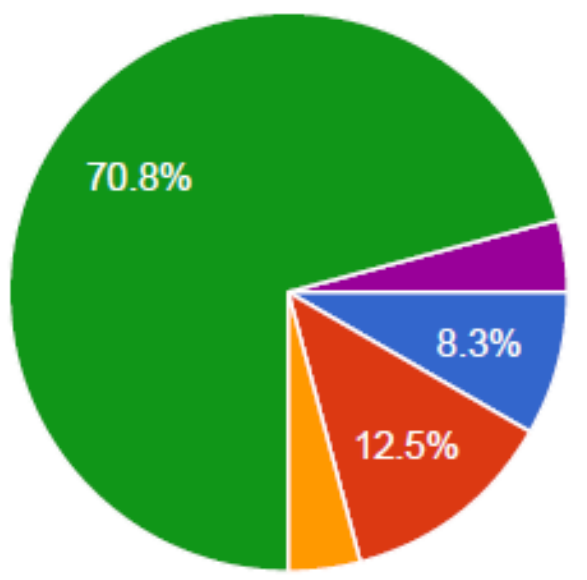

O questionário não se limitou à investigação do Projeto Político-Pedagógico e sua transposição ao curso. Como haviam sido registradas nas dinâmicas várias queixas quanto à didática e à atualização de professores e também tinham sido evidenciadas eventuais faltas de comprometimento, tanto docente quanto discente, esses temas também foram objeto de verificação, e as respostas obtidas tornaram-se importantes orientações para alterações pontuais nas disciplinas.

Conclui-se que, mesmo tendo sido colhidas de forma que beirou o experimental, com imprevistos tanto metodológicos, como situacionais (como no caso da greve), as informações obtidas foram - e continuam sendo - úteis para introduzir aperfeiçoamentos relevantes na nossa formação. O projeto foi encerrado, e sua principal contribuição foi a de pavimentar os caminhos destinados a fornecer subsídios para uma avaliação mais fidedigna e consciente por parte dos alunos.

\section{Considerações Finais}

É certo que a principal função de nossa Graduação é fornecer formações de excelência a nossos alunos, e para isso buscamos as melhores formatações para nosso ensino. Claro que não basta a disponibilização dessas formações para que elas se deem num nível de excelência. Nesse ponto, é óbvio que os alunos, "[...] que têm necessidades a longo prazo ainda não percebidas" (KOTLER, 1994, p. 28), precisam ser motivados ao aprendizado e ao pleno desenvolvimento acadêmico.

\section{O curso combina em dose certa a reflexão crítica e o fazer técnico \\ Deveria ser dada uma ênfase maior à reflexão crítica e mantida a dosagem prática \\ Deveria ser dada uma ênfase maior ao fazer técnico e diminuida a dosagem teórica \\ - Deveria ser dada uma ênfase maior ao fazer técnico, mantida a dosagem teórica \\ - Deveria ser dada uma ênfase maior ao fazer técnico e diminuída a dosagem teórica}

Aumentar a satisfação com os cursos é, não somente, garantia de melhor aprendizado, mas atua paralelamente na diminuição da evasão escolar, favorece a conclusão dos cursos no tempo ideal e eleva a imagem da instituição junto a vários de seus públicos, além de melhorar o nível de relacionamento entre alunos e professores e funcionários.

Percebe-se que, em vários casos, uma significativa parte da insatisfação observada com os cursos pode ser creditada à quebra de expectativas discentes, já que o curso idealizado não se encaixa (ou encaixa-se apenas parcialmente) na formação oferecida. E que muitas vezes as expectativas são criadas por falta de informações concretas ou mesmo falsas percepções dos cursos.

Isso por si só já justifica a necessidade absoluta da divulgação dos Projetos Político-Pedagógicos a nossos alunos. Para que se envolvam mais com seus cursos, para que discutam os métodos e os conteúdos e para que tenham uma participa- 
ção ativa na construção de sua formação. Mas, ao mesmo tempo, o conhecimento do PPP fornece uma base mais real para a avaliação dos cursos e disciplinas: é conhecendo os objetivos, metas e caminhos que se podem avaliar melhor os passos que estão sendo dados. É dentro desse contexto que se situou o projeto Conhecer, Avaliar, Melhorar.

Acreditamos que tenha sido uma experiência pioneira promover a avaliação do curso de Publicidade e Propaganda da ECA, usando o seu PPP como parâmetro. E, ainda que não tenhamos conseguido fugir dos imprevistos, alguns fortuitos, mas vários surgidos pelo ineditismo da iniciativa, temos a certeza de que foram exitosos os resultados.

Vivenciamos os resultados negativos da utilização de uma rede social, o Facebook: acreditávamos que, pelo fato de os alunos estarem plugados na rede o tempo todo, a discussão do PPP pelas páginas da rede social seria espontânea, natural e frequente, e não que o ambiente de comentários rápidos e superficiais não seria adequado para discussões mais sérias e reflexões mais profundas. Pelo equívoco, tivemos que mudar radicalmente a metodologia proposta inicialmente.

Por outro lado, a alteração, utilizando as dinâmicas de grupo em classe, seguidas da aplicação de questionário on-line, mostrou-se bastante adequada, tendo trazido os resultados, que não foram mais ricos devido à situação de greve, que comprimiu o tempo e limitou a aplicação de mais um questionário.

Mesmo assim, os resultados mostram que os alunos querem a divulgação do Projeto Político-Pedagógico e consideram que ele é uma base importante para a discussão e a avaliação do curso. Ao mesmo tempo, as dinâmicas e as respostas ao questionário evidenciaram várias dissonâncias entre o curso idealizado no PPP e a realidade vivenciada por eles nas salas de aula e laboratórios; ficou claro, no final do projeto, que nosso Projeto Político -Pedagógico tem qualidades que, infelizmente, em alguns aspectos não estão presentes na realidade do curso. Mas que, identificadas as defasagens, fica bem mais fácil corrigi-las.

Não se pode, todavia, negar que, por mais que o assunto seja, em tese, fundamental aos alunos, a adesão à discussão vai depender diretamente da motivação deles; o que significa que a campanha de comunicação realizada foi essencial para garantir o conhecimento e a participação discente. Outro aprendizado foi que o PPP é um documento talvez perfeito para ser lido no Conselho Estadual de Educação, mas que tem de ser resumido e vertido numa linguagem mais direta e informal, para atrair a consulta e a discussão entre os alunos.

\section{Nota}

1 Maiores informações sobre o Siga em: siga.ciagri. usp.br/, e sobre Siga/Unidades em: cetilq.sti.usp.br/ competencias/siga-unidades/.

\section{Referências Bibliográficas}

FERREIRA, Luciana M. et al. "Avaliação da Satisfação de Formandos de um Curso de Graduação em Administração de uma Faculdade Pública Paulista". Revista Grad+, vol. 1, n. 2, pp. 31-42, 2016.

FIGUEIRA NETO, Arlindo Ornelas. Em "Curso de Ferreiro"... ou o Uso da Comunicaşão para a Potencialização do Aproveitamento Discente no Ensino de Publicidade e Propaganda na ECA/USP. Tese (Doutorado em Estudo dos Meios e da Produção Mediática), Escola de Comunicações e Artes da Universidade de São Paulo, 2006.

KOTLER, Philip \& KAREN, F. A. Marketing Estratégico para Instituições Educacionais. São Paulo: Atlas, 1994.

RIBEIRO, Júlio. Fazer Acontecer. São Paulo: Cultura, 1998.

\section{Outras Referências:}

http://siga.ciagri.usp.br/frmApresentacao.aspx?Tipo $=\mathrm{IN}$ (Acessado em 2 maio 2017).

http://cetilq.sti.usp.br/competencias/siga-unidades/ (Acessado em 2 maio 2017).

http://jornal.usp.br/institucional/press-release/seminario-siga-discute-a-importancia-do-uso-de-indicadores -para-a-gestao-academical (Acessado em 4 maio 2017). 